\title{
Preliminary report on stone breakage and lesion size produced by a new extracorporeal electrohydraulic (sparker array) discharge device
}

\author{
Bret A. Connors ${ }^{\mathrm{a}}$, Ray B. Schaefer ${ }^{\mathrm{b}}$, John J. Gallagher ${ }^{\mathrm{b}}$, Cynthia D. Johnson ${ }^{\mathrm{a}}$, Guangyan \\ $\mathrm{Li}^{\mathrm{C}}$, Rajash K. Handa ${ }^{\mathrm{a}}$, and Andrew P. Evan ${ }^{\mathrm{a}}$ \\ aDepartment of Anatomy and Cell Biology, Indiana University School of Medicine, Indianapolis, \\ Indiana, USA \\ bPhoenix Science and Technology, Goffstown, New Hampshire, USA \\ 'School of Physics, Northeast Normal University, Changchun, PRC
}

\begin{abstract}
Objective-To determine if an innovative extracorporeal electrohydraulic shock wave device (sparker array) can effectively fracture artificial stones in vitro and in vivo, and if sparker array treatment produces a renal lesion in our pig model of lithotripsy injury. Results of these experiments will be used to help evaluate the suitability of this device as a clinical lithotripter.
\end{abstract}

Methods-Utracal-30 artificial stones were placed in a holder at the focus of the sparker array and treated with 600 shock waves $(21.6 \mathrm{kV}, 60$ shocks/min). Stone fragments were collected, dried and weighed to determine stone breakage. In vivo stone breakage entailed implanting stones into pigs. These stones were treated with 600 or 1200 shock waves and the fragments collected for analysis. Lesion analysis consisted of treating the left kidney of pigs with 1200 or 2400 shock waves and quantitating the hemorrhagic lesion.

Results-In vitro, $71 \pm 2 \%$ of each artificial stone was fractured to $<2 \mathrm{~mm}$ in size. In vivo stone breakage averaged 63\%. Renal injury analysis revealed that only 1 out of 7 kidneys showed evidence of hemorrhagic injury in the treated area.

Conclusions-The sparker array consistently comminuted artificial stones demonstrating its ability to fracture stones like other lithotripters. Also, the sparker array caused little to no renal injury at the settings used in this study. These findings suggest further research is warranted to determine the potential of this device as a clinical lithotripter.

Address correspondence to: Dr. Bret A. Connors, Indiana University School of Medicine, Dept. of Anatomy and Cell Biology, Medical Science Building, Room 0051, 635 Barnhill Drive, Indianapolis, IN 46202. bconnors@iupui.edu.

Publisher's Disclaimer: This is a PDF file of an unedited manuscript that has been accepted for publication. As a service to our customers we are providing this early version of the manuscript. The manuscript will undergo copyediting, typesetting, and review of the resulting proof before it is published in its final citable form. Please note that during the production process errors may be discovered which could affect the content, and all legal disclaimers that apply to the journal pertain.

DECLARATION OF INTEREST STATEMENT

Declaration of Interest: none exist for Bret A. Connors, Cynthia D. Johnson, Guangyan Li, Rajash K. Handa and Andrew P. Evan. Ray B. Schaefer and John J. Gallagher have a patent interest in sparker array technology. 


\section{Keywords}

extracorporeal shock wave lithotripsy; electrohydraulic; artificial stones; acute kidney injury; dualpulse

\section{INTRODUCTION}

The first extracorporeal shock wave lithotripsy (SWL) treatment in the United States employed the electrohydraulic Dornier HM-3, which utilized a spark gap electrode to produce a shock wave (SW). ${ }^{1,2}$ After the debut of the HM-3, other manufacturers introduced lithotripter models that featured spark gap electrodes, as well as machines that used electromagnetic or piezoelectric SW generating technology. ${ }^{3}$ While all fractured stones, none of these technologies are ideal with each having advantages and disadvantages (shock wave power, focal zone size, consistency in acoustic output, etc.) which impact their use as SW sources for clinical lithotripters. ${ }^{4-6}$

In this report we present information on a new technology to generate a focused SW that involves the use of small electrohydraulic ellipsoidal sparker units. The objectives of the current study were to determine if an array of these sparker units (Phoenix Science and Technology sparker array) can effectively comminute model stones and determine if the sparker array (SPA) causes injury to renal tissue during treatment. This analysis will be used to help evaluate whether an array of these sparker units have the potential to produce a SW suitable for use in a clinical lithotripter.

\section{MATERIALS AND METHODS}

\section{Sparker Array}

Details about the development and pressure field of the SPA can be found in Li et al. ${ }^{7}$ and in Supplementary Materials and Methods. Briefly, the SPA treatment head was designed to be mounted onto the frame of a Dornier Compact $\mathrm{S}$ lithotripter (Dornier MedTech, Kennesaw, GA) so that the $\mathrm{x}$-ray $\mathrm{C}$-arm of the Compact $\mathrm{S}$ could be used to target stones during the stone breakage tests, and to target the urinary collection system during evaluation of renal tissue injury. The normal Compact $\mathrm{S}$ treatment head was removed from its mounting plate and the SPA head was mounted in its place (Supplementary Figure 1).

The SPA head consisted of 27 sparker units divided into 3 banks of 9 sparkers each. During the tests listed below the SPA head was operated at a pulse repetition rate of 60 shock waves $(\mathrm{SWs}) / \mathrm{min}$ and an output of 21.6 kilovolts $(\mathrm{kV})$. Also, in most tests only 18 total sparkers were fired (in unison) which produced a typical lithotripter pressure tracing (Supplementary Figure 2) with a peak pressure of 40 megapascal (MPA).

\section{In Vitro Stone Comminution of Artificial Stones}

Eighteen artificial stones were broken inside of an acrylic tank (length $61 \mathrm{~cm} \times$ width $51 \mathrm{~cm}$ $\times$ depth $41 \mathrm{~cm})$ fitted with an acoustic window of Mylar film $(0.13 \mathrm{~mm}$ thick). The water $\left(21-23^{\circ} \mathrm{C}\right)$ in the tank was deionized and degassed to $25 \%-35 \%$ oxygen saturation. The SPA 
treatment head was coupled to the acrylic tank with LithoClear scanning gel (Next Medical Products, Branchburg, NJ). To achieve coupling free of air pockets, a mound of gel was applied to the treatment head. The treatment head was then inflated to contact the Mylar window. Bubbles caught at the interface were removed by suction with an extremely small diameter catheter attached to a syringe.

The artificial stones used in this experiment consisted of Ultracal-30 gypsum stones (U-30), ${ }^{8}$ which were cast in the shape of a cylinder (diameter $6.5-7 \mathrm{~mm} \times$ length $6-7 \mathrm{~mm}$, and see Supplementary Materials and Methods). The stones were immersed in deionized water several days prior to use to remove any trapped air. Once the stones were well hydrated they were placed into a mesh basket with 2-mm openings that was submerged in the treatment tank. The basket was positioned at the geometric focus of the SPA $(n=6), 5 \mathrm{~mm}$ off axis in the positive $\mathrm{X}$ direction $(\mathrm{n}=6)$ or $1 \mathrm{~cm}$ in front of the geometric focus $(\mathrm{n}=6)$. Once properly positioned, $600 \mathrm{SWs}$ were delivered to the stones using the parameters listed above. The stone fragments remaining in the basket ( $\geq 2 \mathrm{~mm}$ in diameter) were then collected, dried and weighed to determine the mass of fragments retained which was then used to calculate a percent of the stone fractured into small pieces. Data are expressed as Mean \pm standard error of the mean (SEM) and statistical analysis was done by one-way ANOVA with pairwise comparisons tested using an F-test. A P value of $<0.05$ was considered significant.

\section{In Vivo Stone Comminution of Implanted Artificial Stones}

The surgical and animal treatment protocols used in both the stone implantation study and kidney injury study were carried out in accordance with the National Institutes of Health Guide for the Care and Use of Laboratory Animals and were approved by the Institutional Animal Care and Use Committee of the Indiana University School of Medicine and Methodist Hospital. The implantation of the artificial stones and subsequent SWL followed the procedure outlined by Paterson et al. ${ }^{9}$ The artificial stones used for implantation were the same as described above.

Two female farm pigs (60-70 kg, Hardin Farms, IN) were anesthetized using ketamine (15$20 \mathrm{mg} / \mathrm{kg}$ ) and xylazine ( $2 \mathrm{mg} / \mathrm{kg}$ ), followed by maintenance using isoflurane (1-3\%). The right and left flank of each pig was shaved to remove any hair that might trap air bubbles. The pigs were then placed on a mechanical ventilator to control respirations. The pigs were initially placed supine in order to assist in the bilateral insertion of 7 French (F) ureteral catheters (Boston Scientific, Natick, MA). Once the catheters were seated, the pigs were moved into a prone position and were given succinylcholine $(1 \mathrm{mg} / \mathrm{kg}$, IV) to reduce respiratory motion during targeting of the renal collection system. X-ray contrast (Isovue-300, Bracco Diagnostics, Princeton, NJ) was used to fill the urine collection system during the percutaneous procedure. A 10-gauge splenic needle was used to create an upper pole caliceal puncture. The tract was then dilated using a 30F Nephromax balloon (Microvasive, Boston Scientific, Watertown, MA) followed by an Amplatz sheath. A flexible nephroscope was used to locate a lower pole minor calyx with an opening large enough to accept an artificial stone. A U-30 artificial stone was inserted down the Amplatz sheath into the kidney and guided into the target minor calyx. One stone was deposited into both the left and right kidney of each one of the pigs. 
After the stone was positioned, the nephroscope was removed and replaced with a 7-10F Cope loop catheter to facilitate drainage of fluid and any air introduced into the collection system during the percutaneous procedure. The Amplatz sheath was then removed and the skin incision was closed with 1-0 silk suture. A minimum of 2 hours was allowed after the incision was closed for the removal of air from the urinary collection system.

After 2 hours the pigs were transported to the lithotripsy suite and secured supine on the treatment table. The SPA treatment head was coupled to the pigs with LithoClear scanning gel. To achieve coupling free of air pockets, a mound of gel was applied to the treatment head. The treatment head was then inflated to contact the body wall of the pigs. The stones were then targeted with the x-ray fluoroscopy system and the SPA was focused on the stones.

For the first pig, both kidneys were treated with 600 SWs (delivered to each stone) at 60 SWs/min and an output of $21.6 \mathrm{kV}$. For the second pig, both kidneys were treated with 1200 SWs (delivered to each stone) using the same lithotripter settings.

After SWL, the kidneys were perfused with physiologic saline to minimize bleeding during dissection. Each kidney with its attached ureter was excised, the renal pelvis was opened and the stone fragments were collected with forceps. The fragments were then transferred to a petri dish containing saline and debrided to remove any coagulated blood and urine proteins. The stone fragments were then passed through the same $2 \mathrm{~mm}$ mesh screen as the in vitro stone breakage experiment. The stone fragments remaining in the basket (larger than $2 \mathrm{~mm}$ in diameter) were then collected, dried and weighed to determine the mass of fragments retained which was then expressed as a percent of the stone fractured during treatment.

\section{Renal Injury Produced By SPA Treatment}

Seven female farm pigs (35-40 kg, Hardin Farms, IN) were anesthetized using ketamine $(15-20 \mathrm{mg} / \mathrm{kg}$ ) and xylazine $(2 \mathrm{mg} / \mathrm{kg})$, followed by maintenance using isoflurane (1-3\%). The left flank of each pig was shaved to remove hair. The pigs were placed supine for the bilateral insertion of 7F ureteral catheters (Boston Scientific, Natick, MA). X-ray contrast (Isovue-300, Bracco Diagnostics, Princeton, NJ) was used to fill the urine collection system during the targeting of the left kidney. Targeting was accomplished by aligning the geometric focus of the SPA head on a lower pole calyx of the left kidney. The SPA treatment head was then coupled to the left flank of the pigs using LithoClear scanning gel following the same procedure as outlined above.

For the first 4 pigs, $1200 \mathrm{SWs}$ were delivered to the left kidney at $60 \mathrm{SWs} / \mathrm{min}$ and an output of $21.6 \mathrm{kV}$. For the last 3 pigs, $2400 \mathrm{SWs}$ were delivered to the left kidney using the same lithotripter settings.

After SWL, the kidneys were perfused with physiologic saline followed by 2 liters of $2.5 \%$ glutaraldehyde (Ladd Industries, Williston, VT) in $0.1 \mathrm{M}$ sodium cacodylate (Electron Microscopy sciences, Hatfield, PA) following the method of Evan et al. ${ }^{10}$ Each kidney with its attached ureter was excised and then stored in fresh fixative until further processing. 
The procedure to quantitate the hemorrhagic lesion produced by SPA treatment followed the technique published by Blomgren et al. ${ }^{11}$ The kidneys were serially sectioned and the sections were photographed so they could be digitized. Areas of hemorrhagic lesion were then identified and measured in the sections to determine the volume of lesion in the entire functional renal volume (FRV) of parenchyma of each kidney.

\section{In Vitro Stone Comminution Using Dual-Pulse Mode}

In the original concept of the SPA, it was anticipated that the SPA may be used to produce dual-pulse SWs during each shock cycle (18 sparkers fired together preceded by, or followed by a different group of 9 sparkers fired together). However, at the time of the evaluation for stone breakage and renal injury, problems with triggering of dual-pulses prevented the testing of the machine in dual-pulse mode. Dual-pulse mode experiments were attempted several weeks later than the present study, but were conducted in a similar fashion to the in vitro stone comminution experiment outlined above. For these experiments, 600 single or dual-pulse SWs were delivered to the stones. This information is included to illustrate that the SPA has the capacity to produce dual-pulses.

\section{RESULTS}

\section{In Vitro Stone Comminution of Artificial Stones}

The results of the in vitro stone breakage are summarized in Table 1. For the stones broken at the geometric focus of the SPA head, $71 \%$ (on average) of each stone was fractured to a size $(<2 \mathrm{~mm})$ that is thought to pass out of the kidney without causing significant problems. Moving away from the focus ( $5 \mathrm{~mm}$ laterally off axis), which typically reduced peak SW pressures by $10 \mathrm{MPa},{ }^{7}$ reduced the ability to fracture the stones to $66 \%$. Interestingly, placing the stones prefocal to the geometric focus (between the shock head and geometric focus) did not improve stone breakage. This position was included because previous work had suggested that stone comminution can be improved by positioning stones $1-2 \mathrm{~cm}$ prefocally during lithotripsy treatment. ${ }^{12}$

\section{In Vivo Stone Comminution of Implanted Artificial Stones}

The results of the in vivo stone breakage for each stone are summarized in Table 2. A picture of a fractured stone inside of a kidney is shown in Figure 1. The stone breakage observed for the stones implanted into pigs was similar to what was observed in vitro. On average, $63 \%$ (600 SWs) to 64\% (1200 SWs) of each stone was fractured into small pieces in vivo, while $71 \%$ of the in vitro stones were pulverized. This occurred in spite of the attenuation of the strength of the SW that normally occurs as the SW passes through the body wall of the pig. $13-15$

\section{Renal Injury Produced By SPA Treatment}

No hemorrhagic injury was observed in any of the kidneys treated with 2400 SWs. Even after each kidney was serially sectioned from one end to the other, no evidence of injury could be found (Supplementary Figure 3). We did, however, find a small lesion (of less than $0.1 \%$ of FRV) in the lower pole of 1 of the $1200 \mathrm{SW}$ treated pigs (Figure 2). This size of 
lesion is near the lower limit of detectability with our method of lesion analysis and represents an extremely small lesion size.

\section{In Vitro Stone Comminution Using Dual-Pulse Mode}

For the dual-pulse mode experiments, firing only the smaller group of 9 sparkers did not fracture the U-30 stones, while firing only the main group of 18 sparkers fractured $84 \%$ of each stone. Operating the SPA in dual-pulse mode appeared to improve stone breakage. The best result occurred when the smaller sparker group was fired before the main group, appearing to fracture $96 \%$ of the stones (Supplementary Table 1).

\section{DISCUSSION}

For in vitro stone breakage, over $70 \%$ of each stone (on average) was fractured into pieces 2 $\mathrm{mm}$ or smaller in size when the artificial stones were positioned at the geometric focus of the SPA (Table 1). Moving off axis by $5 \mathrm{~mm}$ in the in vitro stone breakage tests caused the average stone breakage to fall only slightly, to $66 \%$ (from $71 \%$ ). This suggests that even if targeting of a stone were not perfect, the stone would fracture to a degree similar to stones where targeting is good. Interestingly, placing the stones prefocally did not improve stone fracturing. In fact, fracturing degraded to $54 \%$ when stones were located $1 \mathrm{~cm}$ proximal to the geometric focus. Previous work has shown that this area is where both the peak positive pressure (is equal to pressure at the geometric focus) and peak negative pressure (is $25 \%$ greater than that produced at the geometric focus) are large. ${ }^{7}$ Based on the data for the peak pressure locations it would be reasonable to predict that this region should be the best location for stone fracturing, since the stress on a stone would appear to be at a maximum. However, our results did not support this prediction.

The in vivo stone breakage study data (Table 2) indicated that the in vivo stones broke reasonable well (63\%) compared to in vitro stone breakage (71\%) in spite of the fact that the stones were implanted (see Supplementary Discussion). In fact, the degree of stone breakage, for both in vitro and implanted U-30 stones, observed in the experiments mentioned above is similar to stone breakage reported for several clinical lithotripters ${ }^{8,16-18}$ (see Supplementary Discussion). This suggests that the SPA can operate as a successful lithotripter for clinical work.

In addition to the SPA being evaluated for model stone breakage, we also looked at the amount of tissue damage produced by this machine (see Supplementary Discussion). We did detect small amounts of hemorrhagic injury with the SPA in 1 of 4 kidneys given 1200 SWs. At our maximum dose of 2400 SWs, evidence of hemorrhage was not present in the tissue sections of any of the 3 treated kidneys. This dose was expected to produce some detectible injury like other lithotripters, but none was observed. It has been previously reported that using a SW delivery rate of $60 \mathrm{SWs} / \mathrm{min}$ (the same rate used in the SPA treatments), with the TRT Lithogold-380 or Dornier HM-3 produced a level of injury in treated pig kidneys of around $0.1 \%$ or $0.42 \%$ of the FRV. ${ }^{6,19}$ However, while this slow rate did reduce the amount of hemorrhage to a low level, it did not eliminate the hemorrhagic injury. Because hemorrhage was still present in these kidneys, the slow pulse delivery rate reduction in injury phenomenon cannot completely explain the lack of injury in the SPA treated pigs. 
One possible reason for the lack of tissue hemorrhage is that the SW pulse is not reaching the kidney. However, the observation that implanted stones fracture during SPA treatment suggests that the SPA pulse can and is reaching the targeted calyx in those pigs. Coupling of the pigs to the treatment head with the LithoClear gel was done in the same manner for both the implanted stone pigs and the pigs used for injury analysis, thus coupling should be similar between these two groups. If coupling is the same for both groups, it is reasonable to assume that the SW pulse is also reaching the kidneys of the injury analysis pigs (see Supplementary Discussion).

Preliminary experiments using the SPA in dual-pulse mode indicated that dual-pulse SW treatment is possible with the SPA head as currently designed. Dual-pulses, either ahead or after the main SW pulse, appeared to improve stone fragmentation over single pulse treatment (Supplementary Table 1). Intriguingly, firing the smaller set of sparkers $50 \mu \mathrm{s}$ ahead of the main SW pulse appeared to improve stone breakage the most. This separation in pulse times is long enough that the 2 pulses should not interact with each other directly. The longer separations in pulse times noted in the table are even less likely to result in pulseto-pulse interactions, so another mechanism must be at work to increase stone breakage. Most likely, the second pulse of the dual-pulse combination is influencing the collapse of cavitation bubbles and enhancing cavitation induced stone damage as suggested by several other investigators. ${ }^{20-22}$ Further work will be needed to confirm this observation of increased fragmentation with dual-pulses, to determine the mechanism of this increased breakage, and to determine the optimum interval between pulses for best comminution. Additional work will also need to be done to map the acoustic field of the dual-pulse SWs and measure any possible renal injury from dual-pulse SWs.

\section{CONCLUSIONS}

The SPA consistently comminuted artificial stones demonstrating its ability to fracture stones similar to other lithotripters. However, unlike most other lithotripters, the SPA caused little to no renal injury at the settings used in this study. These findings suggest further research is warranted to determine the potential of this device as a clinical lithotripter.

\section{Supplementary Material}

Refer to Web version on PubMed Central for supplementary material.

\section{Acknowledgments}

This project was supported by National Institutes of Health grants R44 DK-089703 (Small Business Innovation Research) and P01 DK-43881. Authors wish to thank Dr. Ziyue Liu for help with statistical analysis.

\section{References}

1. Lingeman JE, Newman D, Mertz JH, et al. Extracorporeal shock wave lithotripsy: the Methodist Hospital of Indiana experience. J Urol. 1986; 135:1134-1137. [PubMed: 3520015]

2. Drach GW, Dretler S, Fair W, et al. Report of the United States cooperative study of extracorporeal shock wave lithotripsy. J Urol. 1986; 135:1127-1133. [PubMed: 3520014] 
3. Cleveland, RO., McAteer, JA. The physics of shock wave lithotripsy. In: Smith, AD.Badlani, G.Bagley, D., et al., editors. Smith's Textbook of Endourology. 2. Vol. Chap. 38. Hamilton: BC Decker Inc.; 2007. p. 317-332.

4. Lingeman, JE., Matlaga, BR., Evan, AP. Surgical management of upper urinary tract calculi. In: Wein, AJ.Kavoussi, LR.Novick, AC., et al., editors. Campbell-Walsh Urology. 9. Vol. 2. Philadelphia: Saunders; 2007. p. 1431-1507.Chap. 44

5. Faragher SR, Cleveland RO, Kumar S, et al. In vitro assessment of three clinical lithotripters employing different shock wave generators. J Endourol. 2016; 30:560-563. [PubMed: 26918374]

6. Pishchalnikov YA, McAteer JA, Williams JC, et al. Evaluation of the LithoGold LG-380 lithotripter: In vitro acoustic characterization and assessment of renal injury in the pig model. J Endourol. 2013; 27:631-639. [PubMed: 23228113]

7. Li G, Connors BA, Schaefer RB, et al. Evaluation of an experimental electrohydraulic discharge device for extracorporeal shock wave lithotripsy: pressure field of sparker array. J Acoust Soc Am. 2017; 142(5):3147-3153. [PubMed: 29195423]

8. McAteer JA, Williams JC, Cleveland RO, et al. Ultracal-30 gypsum artificial stones for research on the mechanisms of stone breakage in shock wave lithotripsy. Urol Res. 2005; 33(6):429-434. [PubMed: 16133577]

9. Paterson RF, Lingeman JE, Evan AP, et al. Percutaneous stone implantation in the pig kidney: a new animal model for lithotripsy research. J Endourol. 2002; 16(8):543-547. [PubMed: 12470460]

10. Evan AP, Hay DA, Dail WG. SEM of the proximal tubule of the adult rabbit kidney. Anat Rec. 1979; 191(4):397-413.

11. Blomgren PM, Connors BA, Lingeman JE, et al. Quantitation of shock wave lithotripsy-induced lesion in small and large pig kidneys. Anat Rec. 1997; 249:341-348. [PubMed: 9372167]

12. Sokolov DL, Bailey MR, Crum LA, et al. Prefocal alignment improves stone comminution in shockwave lithotripsy. J Endourol. 2002; 16(10):709-715. [PubMed: 12542872]

13. Cleveland RO, Lifshitz DA, Connors BA, et al. In vivo pressure measurements of lithotripsy shock waves in pigs. Ultrasound Med Biol. 1998; 24:293-306. [PubMed: 9550188]

14. Li G, McAteer JA, Williams JC, et al. Effect of the body wall on lithotripter shock waves. J Endourol. 2014; 28(4):446-452. [PubMed: 24308532]

15. Vergunst H, Terpstra OT, Schroder FH, et al. In vivo assessment of shock-waves pressures. Implication for biliary lithotripsy. Gastroenterology. 1990; 99:1467-1474. [PubMed: 2210254]

16. Paterson RF, Lifshitz DA, Lingeman JE, et al. Stone fragmentation during shock wave lithotripsy is improved by slowing the shock wave rate: studies with a new animal model. J Urol. 2002; 168:2211-2215. [PubMed: 12394761]

17. Pishchalnikov YA, Neucks JS, VonDerHaar RJ, et al. Air pockets trapped during coupling in dry head lithotripsy can significantly decrease the delivery of shock wave energy. J Urol. 2006; 176:2706-2710. [PubMed: 17085200]

18. Li G, Williams JC, Pishchalnikov YA, et al. Size and location of defects at the coupling interface affect lithotripter performance. BJU Int. 2012; 110:E871-E877. [PubMed: 22938566]

19. Connors BA, Evan AP, Blomgren PM, et al. Extracorporeal shock wave lithotripsy at 60 shock waves/min reduces renal injury in a porcine model. BJU Int. 2009; 104:1004-1008. [PubMed: 19338532]

20. Loske AM, Prieto FE, Fernandez F, et al. Tandem shock wave cavitation enhancement for extracorporeal lithotripsy. Phys Med Biol. 2002; 47:3945-3957. [PubMed: 12476975]

21. Loske AM, Fernandez F, Zendejas H, et al. Dual pulse shock wave lithotripsy: in vitro and in vivo study. J Urol. 2005; 174:2388-2392. [PubMed: 16280853]

22. Fernandez F, Fernandez G, Loske AM. Treatment time reduction using tandem shockwave for lithotripsy: an in vivo study. J Endourol. 2009; 23:1247-1253. [PubMed: 19580352] 


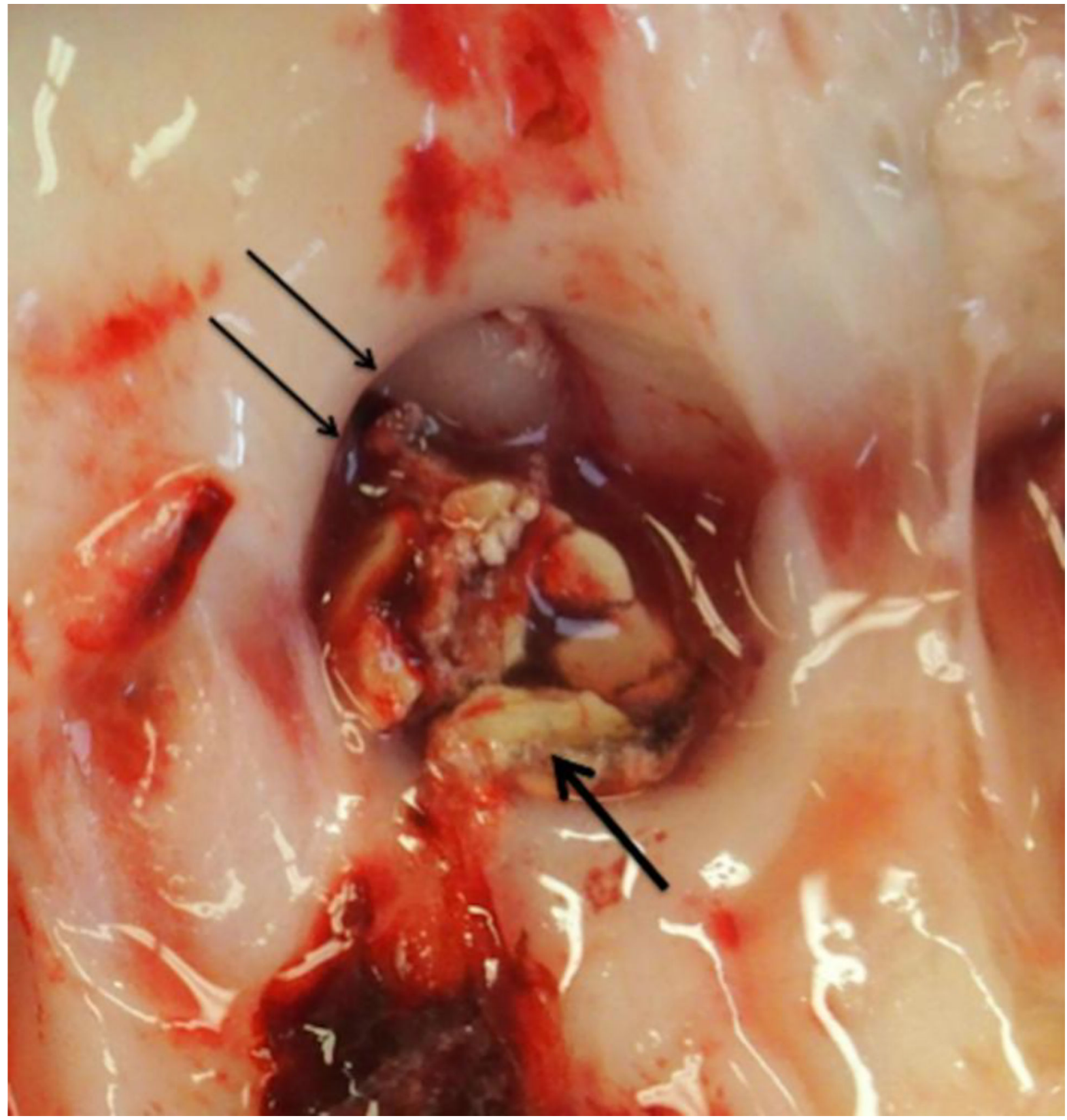

Figure 1.

Photograph of a renal calyx after SW treatment. The calyx (edge of calyx is marked with double arrows) is filled with fluid and a fractured U-30 stone (marked with a single arrow) before stone pieces were collected for analysis. This stone was treated with $600 \mathrm{SWs}$ at a pulse repetition rate of $60 \mathrm{SWs} / \mathrm{min}$ and an output of $21.6 \mathrm{kV}$. (color online, single column width) 


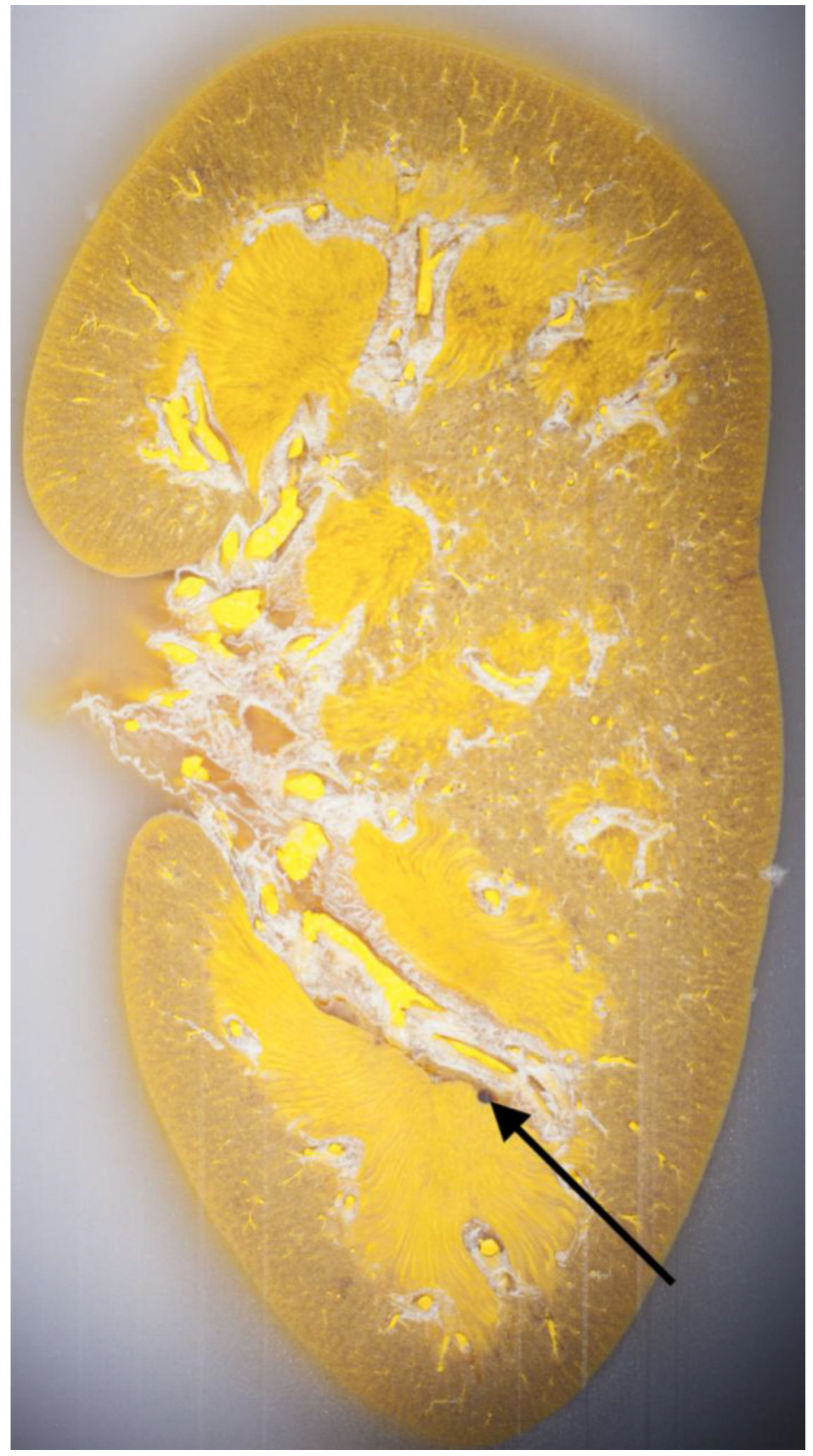

Figure 2.

Photograph of a longitudinal kidney section showing both renal poles. The upper pole is facing the upper part of the page. The focus of the SPA SW was aimed at the lower pole. The kidney was treated with $1200 \mathrm{SWs}$ at a pulse repetition rate of $60 \mathrm{SWs} / \mathrm{min}$ and an output of $21.6 \mathrm{kV}$. Only a very small amount of tissue hemorrhage was observed in that kidney (arrow). The hemorrhage area is located on the tip of a papilla and is small, round and dark. Cranial to caudal length of kidney approx. $11.2 \mathrm{~cm}$. (color online, single column width) 
Table 1

In vitro stone breakage (\% of stone fractured to $<2 \mathrm{~mm}$ ) of $\mathrm{U}-30$ artificial stones at various location in the $\mathrm{SW}$ field (Mean \pm SEM).

\begin{tabular}{lccc} 
& $\begin{array}{c}\text { At Geometric Focus } \\
(\mathbf{N}=\mathbf{6})\end{array}$ & $\begin{array}{c}\mathbf{5} \text { mm Off Focus } \\
(\mathbf{N}=\mathbf{6})\end{array}$ & Pre Focal (N=6) \\
\hline Group Average & $71 \pm 2 \%$ & $66 \pm 3 \%$ & $54 \pm 3 \%$ \\
SignificantDifference & & $\mathrm{P}=0.040$ & $\mathrm{P}=0.0002$ \\
\hline
\end{tabular}

Significant difference refers to difference compared to values at the geometric focus. 


\section{Table 2}

In vivo stone breakage ( $\%$ of stone fractured to $<2 \mathrm{~mm}$ ) of implanted U-30 artificial stones (Mean \pm SEM).

\begin{tabular}{lcc}
\hline & 600 SWs & 1200 SWs \\
\hline Left Kidney & $61.4 \%$ & $56.7 \%$ \\
Right Kidney & $64.8 \%$ & $70.9 \%$ \\
\hline Mean & $63 \pm 2 \%$ & $64 \pm 7 \%$ \\
\hline
\end{tabular}

